\title{
Pesticide residues in cereal crop grains in Poland in 2013
}

\author{
Elżbieta Malinowska • Kazimierz Jankowski • \\ Jacek Sosnowski • Beata Wiśniewska-Kadżajan
}

Received: 30 December 2014 / Accepted: 23 April 2015 / Published online: 7 May 2015

(C) The Author(s) 2015. This article is published with open access at Springerlink.com

\begin{abstract}
This paper presents the results of the audit on pesticide residues in cereal grains throughout Poland in 2013. The number of all samples of cereal grains was 380 . Altogether 292 active substances of plant protection products were checked in the audit. Qualitative and quantative analyses were done according to Polish Standard PN-EN 15562:2008, using the LC-MS/MS technique. The methods (QuEChERS) is based on extraction of residues of plant protection products from a sample using acetonitrile. In the samples analyzed, $62 \%$ of them did not contain any pesticide residues, $34 \%$ of samples of cereal grains contained such residues but below the maximum residue limit, $3 \%$ contained residues over the maximum limit, whereas $1 \%$ of the samples contained illegal substances. The lowest amounts of pesticide residues were found in cereal grains coming from fields with cereal mixtures and in Avena grains, while the highest amounts were in Hordeum and Triticum grains. The substances found most often were fungicide residues. In northern and southern regions of Poland (Silesian, Pomeranian, and Kuyavian-Pomeranian voivodeships), cereal grains with pesticide residues were much more common than in other regions of Poland.
\end{abstract}

Keywords Pesticide residues · Cereals · QuEChERS · Poland

E. Malinowska $(\bowtie) \cdot \mathrm{K}$. Jankowski $\cdot$ J. Sosnowski

B. Wiśniewska-Kadżajan

Department of Grassland and Landscape Architecture, Siedlce

University of Natural Sciences and Humanities, B. Prusa 14

Street, 08 - 110 Siedlce, Poland

e-mail: malinowskae@uph.edu.pl

\section{Introduction}

Plant protection products are a wide group of chemicals which are used against plant pests and diseases so effect crop yields can be higher. However, the growth in biomass is not always accompanied by its higher quality. What is more, chemicals used to protect plants can be dangerous to organisms (Kroes et al. 2000, Gorrido et al. 2003, Qian et al. 2010). To maintain plant food safety, Regulation (EC) No 396/2005 on maximum residue levels of pesticides in or on food and feed of plant and animal origin requires the member states of the European Union to monitor pesticide residue levels in food commodities and submit the monitoring results to EFSA and the European Commission (Regulation 2005, Law on food safety and nutrition 2006). After many years of research, it is possible now to assess health hazards caused by plant protection products (Łozowicka et al. 2012). The same research provides means to identify problems and makes inspection of pesticide use more efficient (Regulation 2010). It is also a legal basis for penal sanctions against those breaking rules and regulations.

The aim of this research is to assess occurrence of residues of plant protection products in cereals according to maximum residue limits (MRL).

\section{Materials and methods}

Plant samples from fields were taken randomly by the staff of State Plant Health and Seed Inspection Services in all abovementioned voivodeships. In the research, the 


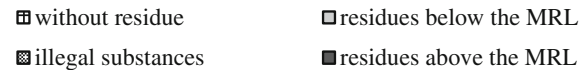

illegal substances

$\square$ residues above the MRL

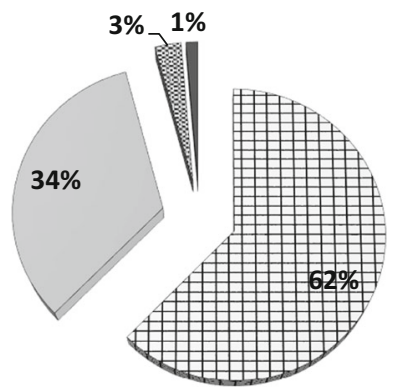

Fig. 1 Residues of plant protection products in cereal crop grains throughout Poland in 2013

following cereals were analyzed: Hordeum L. (37 samples), Triticosecale (68), Triticum (138), Avena L. (30), Secale L. (50), and mixed cereals (57). Altogether in 2013, there were 380 samples with 292 active substances of plant protection products audited. The Department of Food Safety of the Research Institute of Horticulture in Skierniewice is granted a laboratory accreditation certificate according to Polish Standard PN-EN ISO/IEC 17025:2005. Quality control procedures used there were introduced according to SANCO/12459/2011 Method Validation and Quality Control Procedures for Pesticides Residue Analysis in Food and Feed from 01 January 2012 (Method validation 2012). Quantitative and qualitative analyses were done according to Polish Standard PN-EN 15562:2008, using the liquid chromatography coupled to tandem mass spectrometry (LC-MS/MS) technique (Polish Committee for Standardization 2008). The method is based on extraction of residues of plant protection products from a sample using acetonitrile (QuEChERS), and then, the analysis of those products is done using the liquid chromatograph coupled to tandem mass spectrometer (Drożdżyński and Walorczyk 2010). The
QuECHERS method can be modified according to the type of the substance, kinds of matrices tested, equipment used, and analytical technique available in the laboratory (Lehotay et al. 2010). The results of the research on residues of plant protection products in cereal grains are taken from the monitoring of the Research Institute of Horticulture in Skierniewice (Report 2013) (http://www.inhort.pl).

\section{Results and discussion}

Out of 380 samples of cereal crops grains, $62 \%$ did not contain any pesticide residues (Fig. 1). While $34 \%$ of samples contained pesticide residues below maximum residue limits, $3 \%$ contained pesticide residues above maximum residue limits and $1 \%$ of samples contained illegal substances. According to some publications (Lozowicka et al. 2012) in Poland between 2008 and 2012 , there was a fall in the amount of residues of plant protection products in crops. Comparing to the previous years, in 2012, in particular in northeastern Poland, there was a fall in the percentage of fruit and vegetable samples contaminated with those residues. This percentage was considerably lower than in 2008, while in 2011, it amounted to $33.1 \%$, in 2010 to $28.3 \%$, in 2009 to $38.3 \%$, and in 2008 it was $45.5 \%$. It proves that the public awareness of the hazards of using chemicals among farmers is growing. Out of the analyzed cereals (Fig. 2), the smallest amount of plant protection products residues was in mixed cereal grains (below $10 \%$ ) and Avena grains (below $15 \%$ ). Hordeum and Triticum grains contained the highest content of plant protection product residues (over $50 \%$ ). There were illegal substances in four types of cereal grains: Hordeum, Triticosecale, Triticum, and Secale. Pesticide residues
Fig. 2 Residues of plant protection products in cereal crop grains in 2013

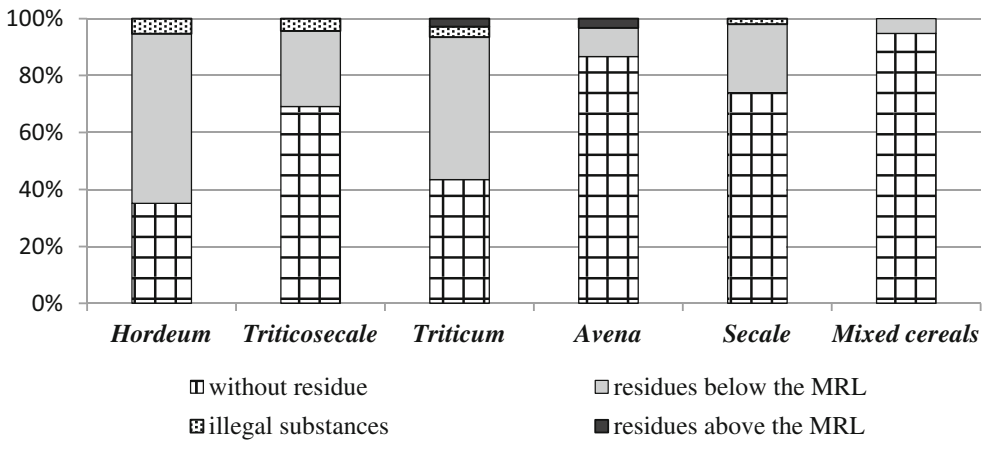


Table 1 The number of samples and the content of active substances in cereal grains in 2013

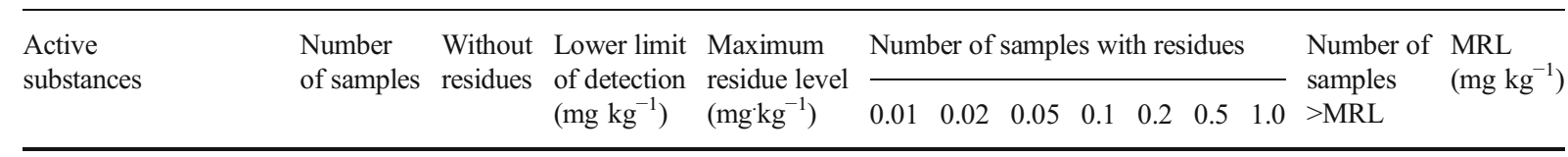

\section{Hordeum}

\begin{tabular}{|c|c|c|c|c|c|c|c|c|c|c|c|c|}
\hline Chlorpyrifos (N) & 37 & 36 & 0.005 & 0.016 & & 1 & & & & & & 0.2 \\
\hline Dimethoate & 37 & 36 & 0.001 & 0.002 & 1 & & & & & & & 0.02 \\
\hline Pirimiphos-methyl & 37 & 30 & 0.005 & 0.38 & & 2 & 3 & 1 & & 1 & & 5 \\
\hline Carbendazim & 37 & 35 & 0.001 & 0.07 & 1 & & & 1 & & & & 2 \\
\hline Thiophanate methyl & 37 & 36 & 0.005 & 0.03 & & & 1 & & & & & 0.3 \\
\hline Azoxystrobin & 37 & 36 & 0.001 & 0.005 & 1 & & & & & & & 0.5 \\
\hline Cyprodinil & 37 & 36 & 0.005 & 0.007 & 1 & & & & & & & 3 \\
\hline Cyproconazole & 37 & 36 & 0.005 & 0.052 & & & & 1 & & & & 0.1 \\
\hline Pencycuron (N) & 37 & 36 & 0.001 & 0.003 & 1 & & & & & & & 0.05 \\
\hline Procymidone $(\mathrm{N})$ & 37 & 36 & 0.005 & 0.01 & & 1 & & & & & & 0.01 \\
\hline Propiconazole & 37 & 36 & 0.005 & 0.019 & & 1 & & & & & & 0.2 \\
\hline Spiroxamine & 37 & 36 & 0.005 & 0.007 & 1 & & & & & & & 0.3 \\
\hline Tebuconazole & 37 & 32 & 0.005 & 0.077 & 1 & 2 & 1 & 1 & & & & 2 \\
\hline \multicolumn{13}{|l|}{ Triticosecale } \\
\hline Chlorpyrifos $(\mathrm{N})$ & 68 & 67 & 0.005 & 0.022 & & & 1 & & & & & 0.05 \\
\hline Dimethoate & 68 & 65 & 0.001 & 0.003 & 3 & & & & & & & 0.05 \\
\hline Pirimiphos-methyl & 68 & 62 & 0.005 & 0.41 & 1 & & 2 & & 2 & 1 & & 5 \\
\hline Carbendazim & 68 & 66 & 0.001 & 0.008 & 2 & & & & & & & 0.1 \\
\hline Propamocarb (N) & 68 & 66 & 0.001 & 0.024 & 1 & & 1 & & & & & 0.1 \\
\hline Epokskonazol & 68 & 66 & 0.005 & 0.012 & 1 & 1 & & & & & & 0.6 \\
\hline Mandipropamid (N) & 68 & 67 & 0.001 & 0.003 & 1 & & & & & & & 0.01 \\
\hline Spiroxamine & 68 & 65 & 0.005 & 0.002 & 3 & & & & & & & 0.05 \\
\hline Tebuconazole & 68 & 67 & 0.005 & 0.012 & & 1 & & & & & & 0.2 \\
\hline \multicolumn{13}{|l|}{ Triticum } \\
\hline Chlorpyrifos (N) & 138 & 137 & 0.005 & 0.005 & 1 & & & & & & & 0.05 \\
\hline Dimethoate & 138 & 135 & 0.001 & 0.009 & 3 & & & & & & & 0.05 \\
\hline Pirimiphos-methyl & 138 & 128 & 0.005 & 0.64 & 2 & 2 & 2 & & 2 & 1 & 1 & 5 \\
\hline Permethrin $(\mathrm{N})$ & 138 & 134 & 0.005 & 0.03 & 3 & 1 & & & & & $1 \mathrm{I}$ & 0.01 \\
\hline Acetamiprid (N) & 138 & 137 & 0.001 & 0.001 & 1 & & & & & & & 0.03 \\
\hline Phenylphenol (N) & 138 & 136 & 0.005 & 0.015 & 1 & 1 & & & & & & 0.05 \\
\hline Imidacloprid & 138 & 137 & 0.01 & 0.011 & & 1 & & & & & & 0.1 \\
\hline Carbendazim & 138 & 131 & 0.001 & 0.025 & 5 & & 2 & & & & & 0.1 \\
\hline Propamocarb (N) & 138 & 137 & 0.005 & 0.013 & & 1 & & & & & & 0.1 \\
\hline Thiophanate methyl & 138 & 137 & 0.005 & 0.033 & & & 1 & & & & & 0.05 \\
\hline Azoxystrobin & 138 & 131 & 0.001 & 0.003 & 7 & & & & & & & 0.3 \\
\hline Boscalid & 138 & 137 & 0.005 & 0.013 & & 1 & & & & & & 0.5 \\
\hline Cyproconazole & 138 & 136 & 0.005 & 0.019 & & 2 & & & & & & 0.1 \\
\hline Epoxiconazole & 138 & 135 & 0.005 & 0.007 & 3 & & & & & & & 0.6 \\
\hline Fenpropimorph & 138 & 134 & 0.001 & 0.015 & 2 & 2 & & & & & & 0.5 \\
\hline Pencycuron (N) & 138 & 137 & 0.001 & 0.003 & 1 & & & & & & & 0.05 \\
\hline Propiconazole & 138 & 137 & 0.005 & 0.057 & & & & 1 & & & $1 \mathrm{~F}$ & 0.05 \\
\hline Spiroxamine & 138 & 131 & 0.001 & 0.017 & 6 & 1 & & & & & & 0.05 \\
\hline
\end{tabular}


Table 1 (continued)

\begin{tabular}{|c|c|c|c|c|c|c|c|c|c|c|c|c|c|}
\hline \multirow{2}{*}{$\begin{array}{l}\text { Active } \\
\text { substances }\end{array}$} & \multirow{2}{*}{$\begin{array}{l}\text { Number } \\
\text { of samples }\end{array}$} & \multirow{2}{*}{$\begin{array}{l}\text { Without } \\
\text { residues }\end{array}$} & \multirow{2}{*}{$\begin{array}{l}\text { Lower limit } \\
\text { of detection } \\
\left(\mathrm{mg} \mathrm{kg}^{-1}\right)\end{array}$} & \multirow{2}{*}{$\begin{array}{l}\text { Maximum } \\
\text { residue level } \\
\left(\mathrm{mg} \cdot \mathrm{kg}^{-1}\right)\end{array}$} & \multicolumn{7}{|c|}{ Number of samples with residues } & \multirow{2}{*}{$\begin{array}{l}\text { Number of } \\
\text { samples } \\
\text { >MRL }\end{array}$} & \multirow{2}{*}{$\begin{array}{l}\text { MRL } \\
\left(\mathrm{mg} \mathrm{kg}^{-1}\right)\end{array}$} \\
\hline & & & & & 0.01 & 0.02 & 0.05 & 0.1 & 0.2 & 0.5 & 1.0 & & \\
\hline Tebuconazole & 138 & 117 & 0.005 & 0.790 & 3 & 9 & 7 & & & 1 & $1^{\mathrm{a}}$ & $1 \mathrm{~F}$ & 0.2 \\
\hline Chlorpropham (N) & 138 & 137 & 0.005 & 0.064 & & & & 1 & & & & $1 \mathrm{H}$ & 0.02 \\
\hline \multicolumn{14}{|l|}{ Avena } \\
\hline Pirimiphos-methyl & 30 & 28 & 0.005 & 0.25 & & & & & 1 & 1 & & & 5 \\
\hline $\operatorname{DEET}(\mathrm{N})$ & 30 & 29 & 0.005 & 0.016 & & 1 & & & & & & $1 \mathrm{I}$ & 0.01 \\
\hline Carbendazim & 30 & 29 & 0.001 & 0.018 & & 1 & & & & & & & 2 \\
\hline \multicolumn{14}{|l|}{ Secale } \\
\hline Chlorpyrifos $(\mathrm{N})$ & 50 & 49 & 0.005 & 0.02 & & & 1 & & & & & & 0.05 \\
\hline Pirimiphos-methyl & 50 & 47 & 0.005 & 0.028 & 1 & & 2 & & & & & & 5 \\
\hline Timetoksam & 50 & 49 & 0.005 & 0.007 & 1 & & & & & & & & 0.005 \\
\hline Carbendazim & 50 & 48 & 0.001 & 0.011 & 1 & 1 & & & & & & & 0.1 \\
\hline Thiophanate methyl & 50 & 49 & 0.005 & 0.033 & & & 1 & & & & & & 0.05 \\
\hline Cyproconazole & 50 & 49 & 0.005 & 0.02 & & & 1 & & & & & & 0.1 \\
\hline Epoxiconazole & 50 & 49 & 0.005 & 0.007 & 1 & & & & & & & & 0.6 \\
\hline Propiconazole & 50 & 49 & 0.005 & 0.013 & & 1 & & & & & & & 0.05 \\
\hline Spiroxamine & 50 & 48 & 0.001 & 0.002 & 2 & & & & & & & & 0.05 \\
\hline \multicolumn{14}{|l|}{ Mixed cereals } \\
\hline Pirimiphos-methyl & 57 & 55 & 0.005 & 0.039 & & 1 & 1 & & & & & & 5 \\
\hline Carbendazim & 57 & 56 & 0.001 & 0.003 & 1 & & & & & & & & - \\
\hline
\end{tabular}

$N$ shortage of registered agents for use, $M R L$ maximum residue limits, $I$ insecticides, $F$ fungicides, $H$ herbicides

${ }^{\text {a }}$ Result relates the whole plant

above maximum residue limits were found in Triticum grains and Avena grains.

In Hordeum grains, there were 13 active substances of different chemical composition (Table 1). Those substances were of the following groups: organophosphorus insecticides, carbaminate fungicides, and other fungicides. Out of 37 analyzed Hordeum samples, illegal substances (chlorpyrifos $0.02 \mathrm{mg} \mathrm{kg}^{-1}$, pencycuron $0.01 \mathrm{mg} \mathrm{kg}^{-1}$, procymidone $0.02 \mathrm{mg} \mathrm{kg}^{-1}$ ) were found in three of them. In the case of Triticosecale, there were many fewer samples containing plant protection products. Out of 68 Triticosecale samples analyzed, there were 21 containing residues of plant protection products. Altogether nine active substances were found including three illegal ones. Those illegal active substances were chlorpyrifos with the concentration of $0.05 \mathrm{mg} \mathrm{kg}^{-1}$, propamocarb $0.01 \mathrm{mg} \mathrm{kg}^{-1}$, and mandipropamid $0.01 \mathrm{mg} \mathrm{kg}^{-1}$. According to some publications (Lu et al. 2000, Figa-Talamanca et al. 2001, Aldrige et al. 2003, Hanke and Jurewicz 2004) they can be mutagenic, carcinogenic and allergenic. Pesticides enter the human body mainly through the digestive system.

Even small amounts of them, if they enter the human or animal body for a longer time, may be hazardous to living organisms, in particular to those organisms which are at the end of the food chain (Kroes et al. 2000, Gorrido et al. 2003).

The greatest number of all cereal samples analyzed was those with Triticum grains, because this cereal accounts for the greatest share in the whole crop area, about $27 \%$ (Central Statistical Office 2013). In 78 samples, out of 138 tested ones, there were residues of 20 different active substances in Triticum grains with seven different illegal substances found in nine samples of those grains. Concentration of two such substances was higher than maximum residue limits, that is permethrin, which is an organophosphorus fungicide, and chlorpropham, which is a herbicide. In three samples with Triticum grains, two more substances above maximum residue limits were found. Those were chemicals of the fungicide group, tebuconazole, two times more 
Fig. 3 The percentage of organosphosphoric herbicides in cereal grains pirimiphos-methyl

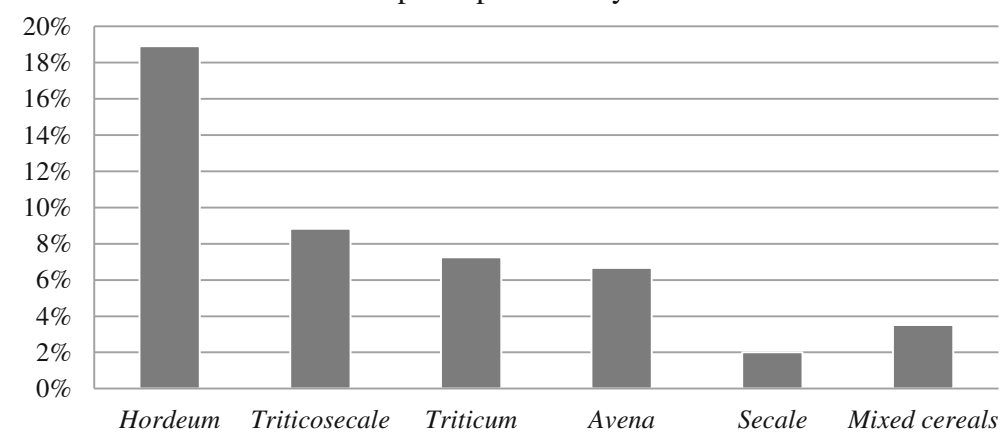

above the maximum residue limit, and propiconazole, two and five times more above the maximum. In one sample with Avena grains, DEET or diethyltoluamide, an insecticide, was found in the amount above the maximum residue limit.

There were no samples with substances over the maximum residue limits in Secale grains. Out of 50 analyzed samples of Secale grains, 13 contained pesticide residues, including one sample with an illegal substance, which was chlorpyrifos. In 57 mixed grains samples, only three contained pesticide residues but illegal substances and plant protection products over maximum residue limits were not found.

Notifications should be prepared according to Rapid Alert System for Food and Feed 2006 if a chemical is used in a way inconsistent with the recommendations or when the content of the chemical in plant products is over the maximum residue limits. Together with a notification, a procedure is started as well as an assessment of consumers' health hazards (Kleter et al. 2009). According to RASFF, in 2013, four substances, if found in Triticum grains, had to be notified to the EU Commission (permethrin, chlorpropham, propiconazole, and tebuconazole) and one substance had to be notified if found in Avena grains (DEET). Besides, illegal substances in all cereal grains, except for mixed cereal crops, should also be notified to RASFF. Podbielska et al. (2013) say that in Poland, illegal substances are quite commonly used in plant protection. Studying vegetable samples cultivated under cover, the authors found the highest amount of pesticide residues in green onion (50\%), pepper (50\%), and tomatoes (45\%). The same research proved the presence of illegal substances used for plant protectionchlorothalonil and chlorpyrifos.
Fungicides, like pirimiphos-methyl, spiroxamine, and tebuconazole, and insecticides were the most common substances found in cereal grains (Łozowicka et al. 2012). However, herbicide residues were only found in Triticum grains. In all cereal grains tested, residues of organosphosphoric insecticides were found, that is pirimiphos-methyl (Fig. 3). In Hordeum grains, the residues of this insecticide were also considerable, with $18.9 \%$. In the other cereal grains, the amount was quite high: $8.82 \%$ in Triticosecale, $7.25 \%$, in Triticum grains, and $6.66 \%$ in Avena grains. The smallest amounts were found in Secale grain, $2 \%$, and mixed grains, $3.5 \%$.

In the research material, different kinds of residues were found with 32 out of 380 samples of cereal grains containing two or more kinds of residues, which accounted for $8.42 \%$ (Table 2). In most cases, those were samples with two active substances $(5.8 \%)$. In one sample of barley and one with wheat, there were five active substances.

There were not many samples with three residues $(1.3 \%)$ or four $(0.79 \%)$. Because plant protection products have become more effective, they are more commonly used and it contributes to accumulation of those products in plants, despite a low content of active ingredient in the substance, and it leads to the fact that maximum residue limits in food and feed are often exceeded. A breakdown by region showed some differences. The highest occurrence of residues was in the Silesian as well as Pomeranian and Kuyavian-Pomeranian voivodeships. In mideastern Poland (Mazovian, Warmian-Masurian, Lesser Poland, and sub-Carpathian voivodeships), there were no samples with a high content of pesticide residues. A high content of residues, above maximum limits, is related to many factors like weather conditions, the way the spray is carried out, pesticide doses, number of insects, the kind of disease, or whether the withdrawal period is maintained. 
Table 2 Cereal grain samples with high occurrence of residues

\begin{tabular}{|c|c|c|}
\hline Cereal species & Type of substances and content in $\mathrm{mg} \mathrm{kg}^{-1}$ & Voivodeships \\
\hline Hordeum & Tebuconazole $(0.01)$, spiroxamine $(0.0066)$ & LBS \\
\hline Hordeum & Pirimiphos-methyl (0.011), azoxystrobin (0.0045) & $\mathrm{KP}$ \\
\hline Hordeum & $\begin{array}{l}\text { Dimethoate }(0.0017) \text {, carbendazim }(0.07) \text {, tebuconazole }(0.077) \text {, } \\
\text { thiophanate methyl }(0.03)\end{array}$ & $\mathrm{SL}$ \\
\hline Hordeum & $\begin{array}{l}\text { Chlorpyrifos }(0.016) \text {, tebuconazole }(0.0076) \text {, cyprodinil }(0.007) \text {, } \\
\text { procymidone }(0.01) \text {, propiconazole }(0.019)\end{array}$ & LBS \\
\hline Triticum & Pirimiphos-methyl (0.64), carbendazim (0.0014) & LD \\
\hline Triticum & Fenpropimorph (0.015), tebuconazole $(0.036)$ & POD \\
\hline Triticum & Dimethoate (0.0096), pirimiphos-methyl (0.018) & $\mathrm{OP}$ \\
\hline Triticum & Azoxystrobin $(0.003)$, cyproconazole $(0.01)$ & $\mathrm{DL}$ \\
\hline Triticum & Azoxystrobin $(0.028)$, tebuconazole $(0.011)$ & $\mathrm{OP}$ \\
\hline Triticum & Cyproconazole (0.019), tebuconazole $(0.031)$ & $\mathrm{OP}$ \\
\hline Triticum & Spiroxamine (0.023), tebuconazole $(0.006)$ & SL \\
\hline Triticum & Pirimiphos-methyl (0.38), carbendazim (0.0027) & SL \\
\hline Triticum & Chlorpyrifos (0.005), phenylphenol (0.005) & POM \\
\hline Triticum & Acetamiprid (0.0013), pencycuron $(0.0031)$ & POM \\
\hline Triticum & Azoxystrobin (0.0033), fenpropimorph (0.0074) & $\mathrm{ZP}$ \\
\hline Triticum & Pirimiphos-methyl (0.034), azoxystrobin (0.0017) & $\mathrm{KP}$ \\
\hline Triticum & Pirimiphos-methyl (0.023), tebuconazole $(0.0056)$ & POM \\
\hline Triticum & Pirimiphos-methyl (0.4), imidacloprid (0.011) & SL \\
\hline Triticum & Carbendazim $(0.038)$, propamocarb $(0.013)$ & POM \\
\hline Triticum & Boscalid (0.013), spiroxamine $(0.017)$, tebuconazole $(0.014)$ & SL \\
\hline Triticum & Dimethoate $(0.028)$, carbendazim $(0.018)$, tebuconazole $(0.039)$ & DL \\
\hline Triticum & $\begin{array}{l}\text { Azoxystrobin }(0.024) \text {, carbendazim }(0.025) \text {, tebuconazole }(0.024) \text {, } \\
\text { thiophanate methyl }(0.033)\end{array}$ & SL \\
\hline Triticum & $\begin{array}{l}\text { Epoxiconazole }(0.007) \text {, permethrin }(0.006) \text {, pirimiphos-Me }(0.005) \text {, } \\
\text { tebuconazole }(0.01)\end{array}$ & $\mathrm{KP}$ \\
\hline Triticum & $\begin{array}{l}\text { Epoxiconazole (0.006), tebuconazole }(0.015) \text {, permethrin }(0.005) \text {, } \\
\text { pirimiphos-methyl }(0.009) \text {, carbendazim }(0.021)\end{array}$ & POM \\
\hline Triticosecale & Mandipropamid (0.0032), propamocarb $(0.024)$ & WLP \\
\hline Triticosecale & Pirimiphos-methyl (0.41), spiroxamine (0.0017) & WLP \\
\hline Triticosecale & Pirimiphos-methyl (0.007), spiroxamine $(0.0016)$ & WLP \\
\hline Triticosecale & Epoxiconazole (0.005), dimethoate $(0.0025)$ & $\mathrm{KP}$ \\
\hline Triticosecale & Epoxiconazole (0.012), dimethoate $(0.0011)$, carbendazim $(0.0026)$ & $\mathrm{KP}$ \\
\hline Secale & Pirimiphos-methyl (0.023), epoxiconazole $(0.007)$ & SL \\
\hline Secale & Carbendazim (0.0042), thiamethoxam (0.0072), thiophanate methyl (0.033) & LBL \\
\hline Secale & Pirimiphos-methyl (0.009), propiconazole (0.013), cyproconazole $(0.02)$ & POM \\
\hline
\end{tabular}

Voivodeships: $L B S$ Lubusz, KP Kuyavian-Pomeranian, SL Silesian, POD Podlasie, $O P$ Opole, POM Pomeranian, ZP West-Pomeranian, $W L P$ Greater Poland, $L B L$-Lublin, $D L$ Lower Silesian, $L D$ Łódz

\section{Conclusions}

The amount of those residues is closely monitored because they can be harmful to living organisms. Analyzing the results of the audit on pesticide residues in Poland it can be said that out of 380 samples of the cereal grains, $62 \%$ did not contain any residues, $34 \%$ residues of plant protection products were below limits, $3 \%$ were above maximum residue limits, while $1 \%$ of samples contained illegal substances.

Grains of Avena and mixed cereals contained the smallest amount of pesticide residues while Hordeum 
and Triticum the highest. The most common substances found were fungicides.

Cereal grains with a high occurrence of residues of plant protection products mainly came from the north and south of Poland because of more intensive farming there.

Open Access This article is distributed under the terms of the Creative Commons Attribution 4.0 International License (http:// creativecommons.org/licenses/by/4.0/), which permits unrestricted use, distribution, and reproduction in any medium, provided you give appropriate credit to the original author(s) and the source, provide a link to the Creative Commons license, and indicate if changes were made.

\section{References}

Aldrige, J. E., Seidler, F. J., Meyer, A., Thillai, I., \& Slotkin, T. A. (2003). Serotonergic systems targeted by developmental exposure to chlorpyrifos: effects during critical periods. Environmental Health Perspectives, 11(14), 1736-1739.

Central Statistical Office, Agriculture (2013). [online] http://www. stat.gov.pl [24.11.2014].

Drożdżyński, D., \& Walorczyk, S. (2010). Validation and uncertainty estimation in pesticide residues analysis of multiclass fruits and $8^{\text {th }}$ European Pesticide Residue Workshop, Strasburg, France, 20-24 June 2010, p.2010.

Figa-Talamanca, I., Traina, M. E., \& Urbani, E. (2001). Occupational exposures to metals, solvents and pesticides: recent evidence no male reproductive effects and biological markers. Occupational Medicine, 51(3), 174-188.

Gorrido, F., Martinez, V. J. L., Moreno, F. M., Olea, S. F., \& Cuadros, R. I. (2003). Determination of organochlorine pesticides by GC-ECD and GC-MS-MS techniques including an evaluation of the uncertainty associated with the results. Chromatographia, 57(3/4), 213-220.

Hanke, W., \& Jurewicz, J. (2004). The risk of adverse reproductive and developmental disorders due to occupational pesticide exposure: an overview of current epidemiological evidence. International Journal of Occupational and Environmental Health, 17(2), 223-243.

Kleter, G. A., Prandini, A., Filippi, L., \& Marvin, H. P. J. (2009). Identification of potentially emerging food safety issues by analysis of report by the European Community's Rapid Alert System for Food and Feed (RASFF) during a four-year period. Food and Chemical Toxicology, 47, 932-950.
Kroes, R., Galli, C., Munro, I., Schilter, B., Trans, L. A., \& Walker, R. (2000). Threshold of toxicological concern for chemical substances present in the diet: a practical tool for assessing the need for toxicity testing. Food and Chemical Toxicology, $38,255-312$.

Law on food safety and nutrition 2006. Dz.U. 171, item. 1225, as amended.

Lehotay, S. J., Ae Son, K., Kwon, H., Koesukwiwat, U., Fu, W., Mastovska, K., Hoh, E., \& Leepipatpiboon, N. (2010). Comparison of QuECHERS sample preparation methods for the analysis of pesticide residues in fruit and vegetables. Journal of Chromatography, 1217, 2548-2560.

Lu, C., Feuske, R. A., Simcox, N. J., \& Kalman, D. (2000). Pesticide exposure of children in on agricultural community: evidence of household proximity to farmland and take home exposure pathways. Environmental Research, 84, 290-302.

Łozowicka, B., Hrynko, I., Rutkowska, E., Jankowska, M., Kaczyński, P., \& Janowicz, T. (2012). Pesticide residues in fruit and vegetable from north-eastern Poland (2008-2011). Progress in Plant Protection, 52(2), 423-430 (in Polish).

Method validation and quality control procedures for pesticides residue analysis in food and feed. Document $\mathrm{N}^{\mathrm{o}} \mathrm{SANCO} /$ 12459/2011 of 01 January 2012.

Podbielska, M., Szpyrka, E., Matyaszek, A., Kurdziel, A., Rupar, J., \& Słowik-Borowiec, M. (2013). Estimation of the dietary exposure associated with pesticide residues in vegetables grown under covers in 2010-2012. Progress in Plant Protection, 53(2), 391-396 (in Polish).

Polish Standard PN-EN 15662: Food of plant origin. Determination of pesticide residues by GC-MS and / or LCMS (/MS) after prior extraction and distribution of acetonitrile and purified by SPE-dispersant QuEChERS method. Polish Committee for Standardization, 2008.

Qian, G., Rimao, H., Feng, T., Xiangwei, W., Xuede, L., Haiqun, C., \& Jun, T. (2010). A multiresidue method for 20 pesticides in Radix paeaniae Alba of Chinese herb by gas chromatography with electron-capture detection. Bulletin of Environmental Contamination and Toxicology, 84, 779-783.

Regulation (EC) No 396/2005 of the European Parliament of the Council of 23 February 2005. On maximum residue levels of pesticides in or on food and feed of plant and animal on their surface, amending Directive 91/414 / EEC. 2005 Acts. U. L $70,16.3 .2005$.

Regulation of the Minister of Agriculture and Rural Development dated 22 November 2010 on the list of active substances authorized for use in plant protection products is prohibited. Dz.U. 235, item. 1547, 2010, as amended.

The report on pesticide residues in agricultural crops in 2013. [online] Access protocol: http://www.inhort.pl [11/05/2014]. 